\title{
SAIFI reliability calculation for the distribution line
}

\author{
Ivan Bandurin ${ }^{1, *}$, Alexey Khaimin ${ }^{1}$ \\ ${ }^{1}$ Pskov State University, Faculty of Computer Science and Power Engineering, 180000, Russia, Pskov, Lenin Square, 2
}

\begin{abstract}
The article for the first time shows the method of calculating the SAIFI reliability index for the distribution line at the design stage. Formulas and examples of calculation of SAIFI indicators for distribution lines of different configurations are given.
\end{abstract}

\section{Introduction}

Government resolution No. 1220 of 31.12.2009 "on the determination of long-term rates of reliability and quality of goods and services supplied" and the relevant order of the Ministry of energy of the Russian Federation of 29 November 2016 №1256 "on approval of Guidelines for the calculation of the level of reliability and quality of goods and services provided for the organization of management of the unified national (all-Russian) electric network and territorial grid organizations" established a mechanism for the relationship between the level of actual reliability and tariffs for electricity transmission grid companies.

The order of the Ministry of energy of the Russian Federation №1256 uses two indicators of the level of reliability of services provided for territorial grid organizations (TGO) - an indicator of the average frequency of termination of electricity transmission to the point of supply of SAIFI and the average duration of the termination of electricity transmission to the point of supply of SAIDI. This situation required the development of methods for calculating the reliability of electricity supply to domestic consumers. In this article the method of calculation of SAIFI reliability index for end users of the distribution line is offered.

When designing a new or reconstructing an operating distribution line, the problem arises of estimating the indices of its reliability. This assessment is necessary primarily for the feasibility study of the construction or reconstruction of the distribution line. In this regard, the purpose of this work is to obtain a method of calculating the SAIFI reliability indicator of the distribution line at the design stage. This confirms the validity of this article.

We will assume that it is advisable to use the same reliability indicators for the distribution line as for the TGO. Reducing the SAIFI value for the distribution line will also reduce the SAIFI value for the entire TGO.

A review of Russian and foreign publications [4-8] showed that the SAIFI reliability index can be determined only by statistical data of operation. Thus, it is possible to obtain an assessment of the reliability of the line before the reconstruction.

\section{Methodology for calculating SAIFI's reliability index}

The mathematics of reliability:

$$
\text { SAIFI }=\frac{\sum_{j=1}^{J} N_{j}}{N_{t}},
$$

where $\mathrm{N}_{\mathrm{j}}$ - the number of points of supply to consumers of network organization services, in respect of which there was a j-th power cut-off within the framework of technological violations, pcs.;

$\mathrm{N}_{\mathrm{t}}$ - the maximum number of points of delivery to consumers of services by the network organization for the $t$-th settlement period of regulation, pcs;

$\mathrm{J}$ - the number of stoppages in supply of electricity in respect of that cheque delivery consumer services network in the t-th current control period, pcs.

The $10 \mathrm{kV}$ distribution network consists of mutually redundant lines of tree configuration with cross sections of wires decreasing to the ends of the line, and TP 10/0.4 $\mathrm{kV}$ mainly on the branches. $10 \mathrm{kV}$ line redundancy can be full and partial. In case of partial reservation, only a part of consumers will receive high-quality electricity.

In rural networks the most commonly used complete transformer substations $10 / 0.4 \mathrm{kV}$ outdoor installation (CTS) and simplified gap-free design switchgear of 10 $\mathrm{kV}$ with transformers 63-250 kVA. For power critical loads using two CTS, between which is mounted the automatic partitioning or a complete checkpoint transformer substation $10 / 0,4 \mathrm{kV}$ that is appended to line $10 \mathrm{kV}$ according to the scheme of input-output.

It is not possible to use formula (1) to calculate SAIFI reliability during the design phase. Therefore, using the basic provisions of the probability theory, we convert the formula (1) to a convenient form for calculations.

In the derivation of the formula, we assume that the distribution line has consumers connected to the scheme

Corresponding author: bandurin_ivan@mail.ru 
of the 2 nd and/or 3 rd category of reliability. In most cases, the distribution line has only one circuit breaker mounted at the beginning of the line. And then, if a short-circuit occurs anywhere in the distribution line, the power switch disconnects all consumers at once. However, with the aim of improving the reliability of a line may be set; and additional circuit breakers (reclosers) in the trunk and/or branch.

Divide a distribution line on $\mathrm{M}$ elementary parcels. The simplest part of the line is:

1) part of a line that does not contain switches,

2) part of a line that contains only one switch.

The accident of the $i$-th section occurs with the frequency of $\lambda_{s . i}$ and leads to the disconnection of consumers, the number of which is equal $N_{s . i}$. The total number of consumers of the distribution line is $N_{5}$.

Let's make an assumption that simultaneous failure of 2 sites is not possible. This assumption is valid for the Poisson distribution law. From a number of publications $[2,3]$ it follows that the discrete case value-the number of trips is subject to the Poisson's law of distribution.

Due to the fact that the failures of the sections of the distribution line represent independent events, then on the basis of the form of the total probability and the formula (1) we obtain:

$$
\text { SAIFI }=\frac{\sum_{i=1}^{M} \lambda_{p l, i} N_{p l, i}}{N_{\Sigma}} .
$$

On the basis of formula (2), we propose the following methods-dick of calculating the indicator SAIFI:

1. Divide a distribution line on M elementary parcels.

2. Find for each $i$-th section of the line the number of failures $\lambda_{i}$ and the number of disconnected $N_{i}$ consumers;

3. Find SAIFI for the distribution line using the formula (2).

Note that the reliability of the power switch is significantly higher than the reliability of the air line. The failure rate of the outdoor unit switch in the stationary state is 0.008 off/year, while the specific rate of sustained air bounce lineages $10 \mathrm{kV}, 1 \mathrm{~km}$ long and $0.25 \mathrm{off} /$ year [3]. So the indicator of failure rate at the switch turned out to be 30 times lower, in order to simplify the calculations, it is permissible to consider the switch to be ideal and not to take it into account in the method of calculating the SAIFI indicator.

\section{Examples of SAIFI reliability calculations}

Consider the different distribution line schemes and determine the SAIFI indicator for each of them. The source data for all the schemes of calculation: $\lambda_{L I}=3$ off/year; $\lambda_{L 2}=4$ off/year; $N_{L 1}=3 \mathrm{PCs} ; N_{L 2}=10$ PCs. Data are taken arbitrarily for convenience and clarity of calculations.

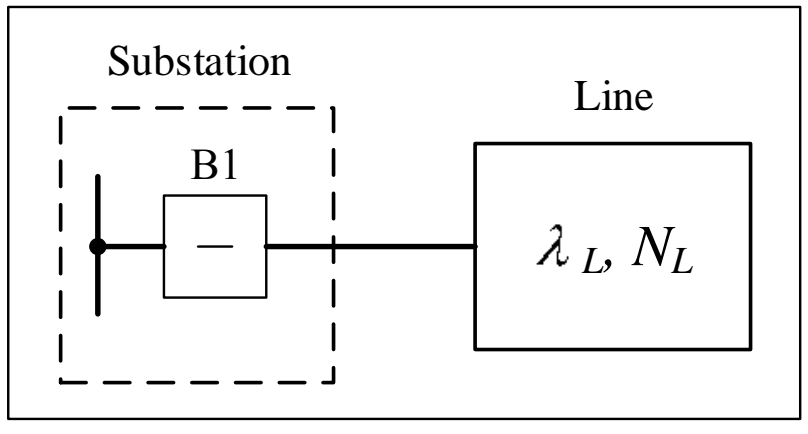

Fig. 1. Block diagram of the simplest distribution line.

Example №1. Let us calculate the SAIFI indicator for the simplest distribution line (Fig. 1). The simplest line is the line that does not contain switching devices.

For the given case $N_{j}=N_{t}$. Therefore,

$$
\text { SAIFI }=\frac{\sum_{j=1}^{J} N_{j}}{N_{t}}=\frac{J N_{t}}{N_{t}}=J=\lambda_{L},
$$

where $\lambda_{L}$ - he number of failures in the line for the year.

Perform the calculation of the SAIFI index for a distribution line, partitioned tables (Fig. 2).

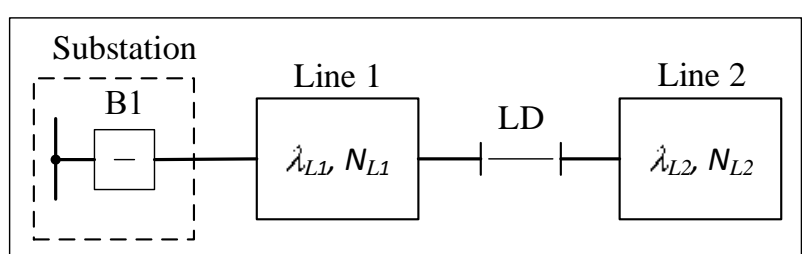

Fig. 2. Structural scheme of distribution lines, partitioned disconnector.

The total number of electricity consumers will be $N_{t}=N_{L 1}+N_{L 2}$. In case of a short circuit on the first or second line, all consumers will be disconnected from the power supply $N_{j L 1}=N_{j L 2}=N_{t}=N_{L 1}+N_{L 2}$. Thus, the SAIFI index for a distribution line, a partitioned switch:

$$
\begin{aligned}
& S A I F I=\frac{\sum_{j=1}^{J} N_{j}}{N_{t}}=\frac{\lambda_{L 1} N_{t}+\lambda_{L 2} N_{t}}{N_{t}}= \\
& =\lambda_{L 1}+\lambda_{L 2}=3+4=7 \frac{\text { outages }}{\text { year }} .
\end{aligned}
$$

Example №2. Find the SAIFI indicator for the switch partitioned distribution line (Fig. 3).

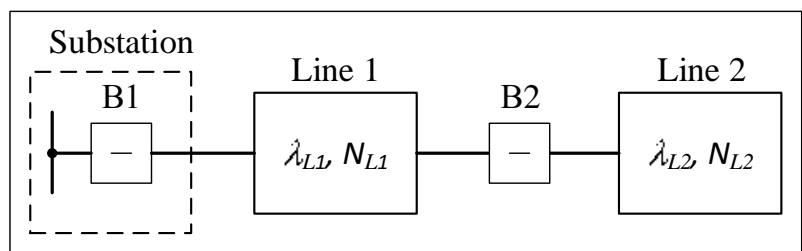

Fig. 3. Structural scheme of distribution lines, a partitioned switch.

The total number of consumers remained the same. In case of an accident on the first line, the number of consumers who will be stopped from supplying 
electricity $N_{j L 1}=N_{t}=N_{L 1}+N_{L 2}$. In case of an accident on the second line $N_{j L 2}=N_{L 2}$. Thus, the SAIFI index for a distribution line, a partitioned switch:

SAIFI $=\frac{\sum_{j=1}^{J} N_{j}}{N_{t}}=\frac{\lambda_{L 1} N_{t}+\lambda_{L 2} N_{\pi 2}}{N_{t}}=$

$=\lambda_{L 1}+\lambda_{L 2} \frac{N_{L 2}}{N_{L 1}+N_{L 2}}=3+4 \frac{10}{3+10}=6,08 \frac{\text { outages }}{\text { year }}$.

Example №3. Find the SAIFI indicator for the switch-partitioned distribution line, if there is a two-way power supply (Fig. 4).

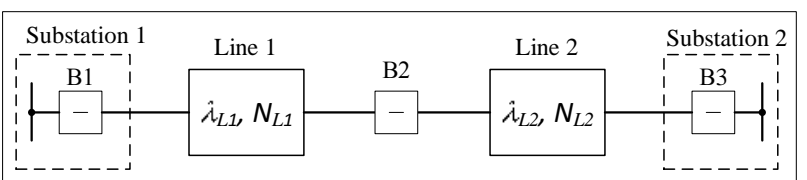

Fig. 4. Structural scheme of distribution lines with dual feed, are interconnected via a switch.

In case of an accident on the first line, the number of consumers who will be stopped from supplying electricity $N_{j L 1}=N_{L 1}$. In the event of a second line failure $N_{j L 2}=N_{L 2}$. So SAIFI performance for the switch partitioned distribution line, in the presence of a two-way power supply:

$$
\begin{aligned}
& \text { SAIFI }=\frac{\sum_{j=1}^{J} N_{j}}{N_{t}}=\frac{\lambda_{L 1} N_{t}+\lambda_{L 2} N_{L 2}}{N_{t}}=\lambda_{L 1} \frac{N_{L 1}}{N_{L 1}+N_{L 2}}+ \\
& +\lambda_{L 2} \frac{N_{L 2}}{N_{L 1}+N_{L 2}}=3 \frac{3}{3+10}+4 \frac{4}{3+10}=3,77 \frac{\text { outages }}{\text { year }} .
\end{aligned}
$$

Having considered the examples, you can compare the performance of SAIFI.

Table 1. Comparison of reliability indices SAIFI.

\begin{tabular}{|c|l|c|}
\hline $\mathbf{N}$ & The event is to improve the reliability & SAIFI \\
\hline 1 & $\begin{array}{l}\text { The partitioning of the line using the } \\
\text { isolator }\end{array}$ & 7 \\
\hline 2 & $\begin{array}{l}\text { The partitioning of the line using the } \\
\text { switch }\end{array}$ & 6,08 \\
\hline 3 & $\begin{array}{l}\text { The partitioning of the line using the } \\
\text { switch when the presence of a bilateral } \\
\text { power }\end{array}$ & 3,77 \\
\hline
\end{tabular}

The analysis of the results shows the effectiveness of measures to improve the reliability of the distribution line, which is confirmed by a decrease in the SAIFI indicator. That, in turn, can be used for a feasibility study of the reconstruction of the distribution line.

Next, we obtain the formulas for calculating the SAIFI indicator of typical distribution line schemes. First, we obtain a formula for calculating the SAIFI indicator for the distribution line partitioned by switches in the trunk.

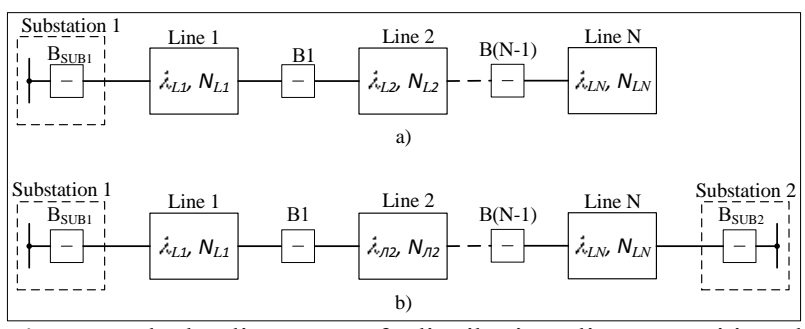

Fig. 5. Block diagrams of distribution lines, partitioned switches in the line a) one-way power supply, b) two-way power supply.

The SAIFI index for the scheme of Fig. 5a:

$$
\text { SAIFI }=\frac{\sum_{i=1}^{N}\left(\lambda_{L i} \sum_{j=i}^{N} N_{L j}\right)}{N_{\Sigma}} .
$$

The SAIFI index for the scheme of Fig. 5b:

$$
\text { SAIFI }=\frac{\sum_{i=1}^{N} \lambda_{L i} N_{L i}}{N_{\Sigma}} .
$$

Get the formula for calculating the SAIFI indicator for the distribution line, partitioned switches on the branches (Fig. 6).

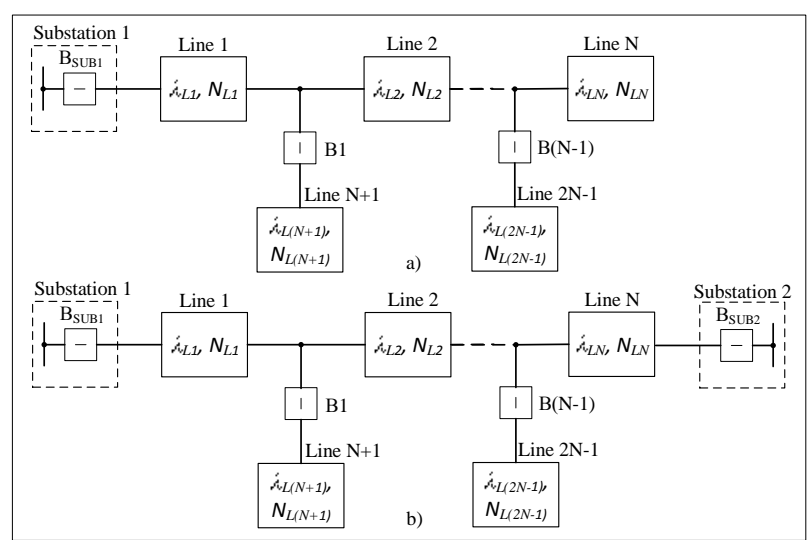

Fig. 6. Block diagrams of distribution lines, partitioned switches on branches a) one-way power supply, b) two-way power supply.

The SAIFI index for the scheme of Fig. $6 a$ and $6 \mathrm{~b}$ :

$$
S A I F I=\sum_{i=1}^{N} \lambda_{L i}+\frac{\sum_{i=N \cdot 1}^{2 N-1} \lambda_{L i} N_{L i}}{N_{\Sigma}} .
$$

Get the formula for calculating the SAIFI indicator for the distribution line, partitioned switches in the trunk and branches (Fig. 7).

The SAIFI index for the scheme of Fig. 7a:

$$
S A I F I=\frac{\sum_{i=1}^{N}\left(\lambda_{L i}\left(\sum_{j=i}^{N} N_{L j}+\sum_{j=N+i}^{2 N-1} N_{L j}\right)\right)}{N_{\Sigma}}+\frac{\sum_{i=N \cdot * 1}^{2 N-1} \lambda_{L i} N_{L i}}{N_{\Sigma}} .
$$

The SAIFI index for the scheme of Fig. $7 \mathrm{~b}$ :

$$
\text { SAIFI }=\frac{\sum_{i=1}^{2 N-1} \lambda_{L i} N_{L i}}{N_{\Sigma}} .
$$




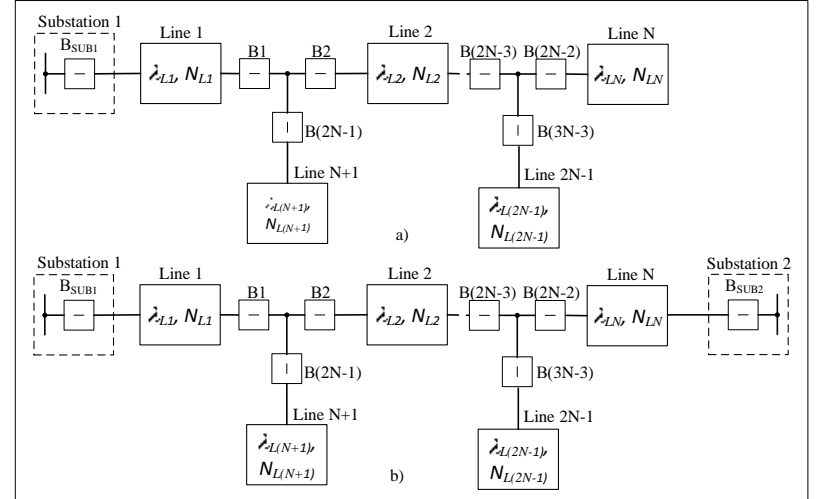

Fig. 7. Block diagrams of distribution lines, partitioned switches in the trunk and on the branches a) one-way power supply, b) two-way power supply.

Example №. 4. Consider the schematic diagram of the distribution line prototype, which was one of the existing $10 \mathrm{kV}$ distribution line of the Pskov region. The final data for the calculation of reliability were taken from the literature [3]. These data reflect the average level of reliability of the elements of rural networks in the European part of the country. As shown by the relevant studies carried out by the author [4] in JSC "firm ORGRES", the indicators of damage to the elements of electrical networks have adequate reliability, because they are not subject to administrative influence.

The results of SAIFI calculation (table 2) for the distribution line are presented below.

Table 2. Calculation of the average number of outages.

\begin{tabular}{|c|c|c|c|c|}
\hline № & Equipment & Number & $\begin{array}{c}\text { Failure } \\
\text { rate, } \\
\text { year }^{-1}\end{array}$ & $\begin{array}{l}\text { Average } \\
\text { number of } \\
\text { failures } \\
\text { per year }\end{array}$ \\
\hline 1 & $\begin{array}{l}\text { High } \\
\text { voltage line } \\
\text { with AC } \\
\text { wire } \\
\end{array}$ & 20,55 & 0,25 & 5,14 \\
\hline 2 & $\begin{array}{l}\text { High } \\
\text { voltage line } \\
\text { with SIW } \\
\text { wire } \\
\end{array}$ & 0,492 & 0,1 & 0,05 \\
\hline 3 & Cable line & 0,5 & 0,075 & 0,04 \\
\hline 4 & $\begin{array}{l}\text { Linear } \\
\text { disconnector }\end{array}$ & 4 & 0,01 & 0,04 \\
\hline 5 & CTS & 14 & 0,07 & 0,98 \\
\hline \multicolumn{4}{|c|}{ Subtotal: } & 6,24 \\
\hline
\end{tabular}

As follows from table 2, the average number of emergency breaks in power supply to consumers of the distribution line $\lambda_{L}=6.24$ outages/year.

Thus, according to the formula (4) for the distribution line, we obtain that, as shown by the experimental data for the $10 \mathrm{kV}$ distribution line of the Pskov region, the SAIFI indicator is $\lambda_{L e}=5.7$ outages/year. The theoretical value of the SAIFI indicator differs from the value of the operation data by no more than $10 \%$. This confirms the adequacy of the method of calculation of the SAIFI indicator.

\section{Conclusion}

In the article, the methodology for calculating the SAIFI reliability indicator of the distribution line for the design phase was developed for the first time. Formulas and examples of calculation of SAIFI indicators for typical distribution lines are given. The developed methodology can be used for the feasibility study of the construction of new distribution lines or the reconstruction of existing lines in order to improve reliability.

\section{References}

1. Nepomnyashchy V. A. Reliability of work of elements of electric networks of 1150-35 kV / / Energoekspert. - 2012. - №4. - P. 26-40.

2. Polovko A. M., Gurov S. V. Fundamentals of reliability theory. 2nd ed., Rev. and extra - $\mathrm{SPb}$.: BHV-Petersburg, 2006. - P.43-45.

3. Pruss V. L., Tislenko V. V. Improving the reliability of rural electrical networks. - L.]. Leningr. otd., $1989-208$ p.

4. Tereshko O. A. Innovative methods of control of reliability of distribution electric networks / / Methodical questions of research of reliability of big systems of power: Collection of scientific. art / ed. N. I. Voropay, M. A. Korotkevich, A. A. Mikhalevich. - - Minsk: publishing House of BSTU, 2015. - Issue. 66. - C. 206-210..

5. IEEE Guide for Electric Power Distribution Reliability Indices - Redline," in IEEE Std 13662012 (Revision of IEEE Std 1366-2003) - Redline , vol., no., pp.1-92, May 312012

6. M. Papic and R. N. Allan, "Comparison of alternative techniques for the reliability assessment of distribution systems," 1991 Third International Conference on Probabilistic Methods Applied to Electric Power Systems, London, 1991, pp. 174-179

7. R. Allan and R. Billinton, "Power system reliability and its assessment. III. Distribution systems and economic considerations," in Power Engineering Journal, vol. 7, no. 4, pp. 185-192, Aug. 1993.

8. P. K. Goswami, S. Chowdhury, S. P. Chowdhury, Y. H. Song and J. K. Das, "Reliability evaluation of distribution system," 2007 42nd International Universities Power Engineering Conference, Brighton, 2007, pp. 158-166 